This is the author's final, peer-reviewed manuscript as accepted for publication. The publisher-formatted version may be available through the publisher's web site or your institution's library.

\title{
Ectopic expression of a maize calreticulin mitigates calcium deficiency-like disorders in SCAX1-expressing tobacco and tomato
}

Qingyu Wu, Toshiro Shigaki, Jeung-Sul Han, Chang Kil Kim, Kendal D. Hirschi, Sunghun Park

\section{How to cite this manuscript}

If you make reference to this version of the manuscript, use the following information:

Wu, Q., Shigaki, T., Han, J.-S., Kim, C. K., Hirschi, K. D., \& Park, S. (2012). Ectopic expression of a maize calreticulin mitigates calcium deficiency-like disorders in SCAX1expressing tobacco and tomato. Retrieved from http://krex.ksu.edu

\section{Published Version Information}

Citation: Wu, Q., Shigaki, T., Han, J.-S., Kim, C. K., Hirschi, K. D., \& Park, S. (2012). Ectopic expression of a maize calreticulin mitigates calcium deficiency-like disorders in sCAX1-expressing tobacco and tomato. Plant Molecular Biology, 80(6), 609-619.

Copyright: (C) Springer Science+Business Media Dordrecht 2012

Digital Object Identifier (DOI): doi:10.1007/s11103-012-9970-6

Publisher's Link: http://link.springer.com/article/10.1007\%2Fs11103-012-9970-6

This item was retrieved from the K-State Research Exchange (K-REx), the institutional repository of Kansas State University. K-REx is available at http://krex.ksu.edu 
1 Ectopic expression of a maize calreticulin mitigates calcium

2 deficiency-like disorders in $s C A X 1$-expressing tobacco and tomato

Qingyu Wu, Toshiro Shigaki, Jeung-Sul Han, Chang Kil Kim, Kendal D. Hirschi, Sunghun Park

Qingyu Wu, Sunghun Park

Department of Horticulture, Forestry and Recreation Resources, Kansas State

University, Manhattan, KS 66506, USA

Toshiro Shigaki

Papua New Guinea National Agricultural Research Institute, Bubia, Ten Mile, P. O. Box 1639, Lae, Morobe Province, Papua New Guinea

Jeung-Sul Han

Department of Ecological Environment, Kyungpook National University, Sangju 742-711, Republic of Korea

Chang Kil Kim

Department of Horticultural Science, Kyungpook National University, Sangju 742-711, Republic of Korea

Kendal D. Hirschi

United States Department of Agriculture/Agricultural Research Service, Children's Nutrition Research Center, Baylor College of Medicine, Houston, TX 77030, USA

Author for correspondence:

Sunghun Park

Tel: +1 $7855324412 \quad$ Fax: +1 7855326949

Email:shpark@ksu.edu

A total word count: $\mathbf{4 , 4 0 5}$

Number of figures: 5

Supplementary material: 4 


\section{Abstract}

2 Deregulated expression of an Arabidopsis $\mathrm{H}^{+} / \mathrm{Ca}^{2+}$ antiporter (sCAX1) in agricultural

3 crops increases total calcium $\left(\mathrm{Ca}^{2+}\right)$ but may result in yield losses due to $\mathrm{Ca}^{2+}$

4 deficiency-like symptoms. Here we demonstrate that co-expression of a maize

5 calreticulin (CRT, a $\mathrm{Ca}^{2+}$ binding protein located at endoplasmic reticulum) in

$6 s C A X 1$-expressing tobacco and tomato plants mitigated these adverse effects while

7 maintaining enhanced $\mathrm{Ca}^{2+}$ content. Co-expression of $C R T$ and $s C A X 1$ could alleviate

8 the hypersensitivity to ion imbalance in tobacco plants. Furthermore, blossom-end rot

9 (BER) in tomato may be linked to changes in CAX activity and enhanced $C R T$ expression mitigated BER in $s C A X 1$ expressing lines. These findings suggest that

11 co-expressing $\mathrm{Ca}^{2+}$ transporters and binding proteins at different intracellular

12 compartments can alter the content and distribution of $\mathrm{Ca}^{2+}$ within the plant matrix.

14 Key words: Calcium CAX CRT Co-expression Tomato 
3 In vegetables and fruits, calcium $\left(\mathrm{Ca}^{2+}\right)$ deficiency is a critical factor reducing their

4 quality and yield due to $\mathrm{Ca}^{2+}$-related physiological disorders, such as blossom-end rot

5 (BER) in tomato, pepper, eggplant and melon, tipburn in lettuce, celery and cabbage,

\section{Introduction}

and bitter pit in apple fruit (White and Broadley 2003; Dayod et al. 2010; de Freitas et al. 2011). Moreover, low human dietary intake of $\mathrm{Ca}^{2+}$ has been associated with a disease, osteoporosis, which may lead to a bone fracture (Bachrach 2001). Plant-based foods are good sources of dietary $\mathrm{Ca}^{2+}$; however, increased amounts in particular foods may help ameliorate the incidence of osteoporosis caused by consumption of inadequate dietary $\mathrm{Ca}^{2+}$ (Hirschi 2009; Park et al. 2009). Therefore, a better understanding of $\mathrm{Ca}^{2+}$ improvement in plant cells is required in order to positively impact human nutrition and improve fruit and vegetable production.

Calcium is unique amongst the elements in plants and animals because it plays both a pivotal structural and, an essential, signaling role (White and Broadley 2003; Hirschi 2004). Consequently steep gradients for $\mathrm{Ca}^{2+}$ exist across cell membranes and cell endomembranes: the plasma membrane (PM), tonoplast (TN), and the endoplasmic reticulum (ER). Gradients across these organelles are important for normal cellular function and for the regulation of metabolic processes which requires punctilious regulation of cytosolic $\mathrm{Ca}^{2+}$. These gradients are established by a dynamic balance between influx and efflux of $\mathrm{Ca}^{2+}$ across each of the cellular membranes. 
The concentration gradient of $\mathrm{Ca}^{2+}$ across the $\mathrm{TN}$ is established partially by high-capacity $\mathrm{H}^{+} / \mathrm{Ca}^{2+}$ antiporters (Zhao et al. 2009). Among them, CAXs ( $\underline{\text { Cation }} / \mathrm{H}^{+}$ exchangers), a group of high-capacity, low-affinity transporters that export cations out of the cytosol to maintain ion homeostasis across biological membranes (Pittman and Hirschi 2003), have been physiologically characterized from a variety of plants. The first Arabidopsis $C A X$ gene, $C A X 1$ was identified by its ability to suppress the $\mathrm{Ca}^{2+}$ sensitivity of a yeast mutant deleted in vacuolar $\mathrm{Ca}^{2+}$ transport (Hirschi et al. 1996). CAX1 contains an additional 36 amino acid at its $\mathrm{N}$-terminus that reduces the transport activity in both yeast and plant expression assays (Pittman and Hirschi 2001; Mei et al. 2007). When the N-terminal truncated version (sCAX1) is ectopically expressed in potato, carrot and lettuce, $\mathrm{Ca}^{2+}$ content in their edible tissues increases (Park et al. 2005b; Park et al. 2009). However, in some cases, these changes also produce deleterious phenotypes that impact yield (Hirschi 1999; Park et al. 2005a). Tempering expression of $s C A X 1$ driven by a different promoter results in healthier plants but they often accumulate less $\mathrm{Ca}^{2+}$ (Park et al., 2005a).

Tobacco lines expressing $s C A X 1$ increase $\mathrm{Ca}^{2+}$ content in their tissues, but also display severe $\mathrm{Ca}^{2+}$ deficiency-like symptoms, such as apical leaf tip burning and sensitivity to ion imbalances (Hirschi 1999). In addition, while the fruits of $\mathrm{s} C A X 1$-expressing tomato plants accumulate higher total $\mathrm{Ca}^{2+}$ than vector control plants, the $s C A X 1$-expressing tomatoes show increased incidence of distinct necrotic lesions in the distal portion of fruits, termed blossom-end rot (BER), which is presumed to be caused by aberrant $\mathrm{Ca}^{2+}$ homeostasis in fruit cells (Park et al. 2005a). 
1 These phenomena are an obstacle for the development of $\mathrm{Ca}^{2+}$-biofortified crops.

Our working hypothesis is that the increased expression of $s C A X 1$ in conjunction with $\mathrm{Ca}^{2+}$ binding proteins on another endomembrane may reduce these deleterious phenotypes. Calreticulin (CRT), a $\mathrm{Ca}^{2+}$-binding protein mainly resident in the ER, has been known as an effective $\mathrm{Ca}^{2+}$ buffer protein that may allow the transient storage of $\mathrm{Ca}^{2+}$ and play a role in stress responses (Jia et al. 2009).

Over-expression of a maize $C R T$ cDNA in tobacco suspension cells results in a two-fold increase in $\mathrm{Ca}^{2+}$ accumulation in the ER-enriched fraction in vitro (Persson et al. 2001) and could improve growth of tobacco cell suspensions in high-Ca ${ }^{2+}$ medium (Akesson et al. 2005).

Here, we express a maize $C R T$ in $s C A X 1$-expressing tobacco and tomato plants to test our hypothesis if the expression of $C R T$ gene can mitigate $\mathrm{Ca}^{2+}$-related cellular dysfunction resulted from expressing of $s C A X 1$ in tobacco and tomato plants while maintaining enhanced $\mathrm{Ca}^{2+}$ content. Our findings suggest that co-expressing transporters and binding-proteins may be a means of boosting plant nutrient content without adversely affecting yield. To our knowledge, this study represents the first attempts to increase the $\mathrm{Ca}^{2+}$ content of plants using co-expression of two genes which play important roles in the regulation of $\mathrm{Ca}^{2+}$.

\section{Materials and Methods}


1 The pCaMV::sCAX1 [sCAX1 driven by the cauliflower mosaic virus (CaMV) 35S

2 promoter] expression vector was previously constructed and described (Park et al.

3 2005b) (Fig. 1a). The maize CRT (NCBI accession number: AF190454) open reading

4 frame was cloned into the SacI site of pE1775 binary vector (Lee et al. 2007) (Fig. 1a),

5 and the pE1775::CRT and pCaMV::sCAX1 were introduced into Agrobacterium

6 tumefaciens strain LBA 4404 (Hoekema et al. 1983) using the freeze-thaw method

7 (Holsters et al. 1978). The pE1775 expression vector contains a superpromoter, which

8 consists of a trimer of the octopine synthase transcriptional activating element affixed

9 to the mannopine synthase 2' (mas2') transcriptional activating element plus minimal

10 promoter, and has been proved to be a strong promoter when being expressed in

11 tobacco and maize (Lee et al. 2007). 35SCaMV promoter was intentionally avoided to

12 drive $C R T$ gene because previous studies suggest that two transgenes driven by the

13 same promoter might cause silencing of one or both genes (Park et al. 1996).

\section{Plant material, transformation, and growth conditions}

Tobacco (Nicotiana tabacum L.) cultivar KY14 was used in this study. Tobacco transformation was performed via Agrobacterium-mediated leaf disk transformation method as previously described (Horsch et al. 1985). Seeds were surface-sterilized and germinated on MS inorganic salt medium (Murashige and Skoog 1962) with $30 \mathrm{~g}$ $\mathrm{l}^{-1}$ sucrose, $\mathrm{pH}$ 5.7, and solidified using $8 \mathrm{~g} \mathrm{l}^{-1}$ agar (PhytoTechnology, Shawnee

21 Mission, KS, USA). Transformants were selected on standard medium containing 100

$22 \mu \mathrm{g} \mathrm{ml}^{-1}$ kanamycin for $s C A X 1-, 50 \mu \mathrm{g} / \mathrm{mL}$ hygromycin for $C R T$-, and $100 \mu \mathrm{g} \mathrm{ml}^{-1}$ 
1 kanamycin plus $50 \mu \mathrm{g} \mathrm{ml}^{-1}$ hygromycin for $s C A X 1$ - and $C R T$-co-expressing tobacco.

2 Tobacco plants were grown in a greenhouse as previously described (Hirschi 1999).

3 For ion sensitivity analysis, surface-sterilized seeds were germinated in MS media.

4 Ten days after plating, the seedlings were transferred to MS media supplemented with

5 the appropriate ion. To make media deficient in $\mathrm{Ca}^{2+}$, we removed the $\mathrm{CaCl}_{2}$ from the

6 nutrient solution. The T1 and T2 tobacco plants were grown in the greenhouse under a

7 16-h photoperiod within a temperature range of $25^{\circ} \mathrm{C}$ to $30{ }^{\circ} \mathrm{C}$. Leaves from

8 2-month-old T2 generation tobacco plants were sampled for $\mathrm{Ca}^{2+}$ concentration

9 analysis.

Tomato (Solanum lycopersicum 'Rubion') transformation was performed via

11 Agrobacterium-mediated transformation method using cotyledon and hypocotyls

explants as previously described (Park et al. 2003). A. tumefaciens LBA 4404 was

used for generating stable transgenic plants. After inoculation with A. tumefaciens, the plant cultures were maintained at $25^{\circ} \mathrm{C}$ under a 16-h photoperiod. After 6 to 8 weeks, regenerated shoots were transferred to rooting medium for additional six weeks. The temperature of the greenhouse was maintained within a range of $25^{\circ} \mathrm{C}$ to $28{ }^{\circ} \mathrm{C}$. conditions described above. We manually pollinated the flowers and marked the date was examined. The fruits of 40-day after pollination (40 DAP) were harvested for $\mathrm{Ca}^{2+}$ content determination. 


\section{DNA isolation and DNA gel blot analysis}

Genomic DNA of tobacco and tomato was isolated from $100 \mathrm{mg}$ of fresh leaves using the DNeasy Plant Mini-Kit (Qiagen, Valencia, CA, USA) according to the manufacturer's instructions. DNA gel analysis was carried out as described previously (Park et al. 2009). Genomic DNA (5-10 $\mu \mathrm{g})$ was digested with $\mathrm{XbaI}$, separated in a $0.9 \%(\mathrm{w} / \mathrm{v})$ agarose gel by electrophoresis and blotted on to a nylon membrane (Zeta-Probe GT membrane, BioRad Laboratories, Hercules, CA, USA). The probe for the $s C A X 1$ gene was isolated by digesting pBluscript::sCAX1 (Park et al. 2009). The membranes were pre-hybridized at $65^{\circ} \mathrm{C}$ in $7 \%$ sodium dodecylsulphate (SDS) and $0.25 \mathrm{M} \mathrm{Na}_{2} \mathrm{HPO}_{4}$ for 3 hours, and then hybridized overnight at $65^{\circ} \mathrm{C}$ in the same solution containing the probe labeled by NEBlot Phototope Kit (New England Biolabs, Beverly, MA, USA). Membranes were washed twice for 40 min each with $20 \mathrm{mM}$ $\mathrm{Na}_{2} \mathrm{HPO}_{4}$ and $5 \%$ SDS at $65{ }^{\circ} \mathrm{C}$ and then washed twice again for 30 min each with 20 $\mathrm{mM} \mathrm{Na} 2 \mathrm{HPO}_{4}$ and $1 \%$ SDS at $65^{\circ} \mathrm{C}$. The signal was detected using the Phototope-Star Detection Kit (New England Biolabs).

\section{RNA isolation, RT-PCR, and RNA gel blot analysis}

Total RNA of tobacco and tomato was extracted from leaves using RNeasy Plant Mini Kit (Qiagen, Valencia, CA, USA) according to the manufacturer's instructions. RNA for RT-PCR was treated with RNase-free DNase prior to the synthesis of first-strand cDNA by oligo (dT) priming using moloney murine leukaemia virus-reverse transciptase (BD Biosciences Clontech, Palo Alto, CA, USA). One microliter of the 
reverse transcription reaction solution was used as a template in a $25 \mu 1$ PCR solution. Total RNA $(7 \mu \mathrm{g})$ was separated on a $1.2 \%$ agarose gel containing $1.5 \%$ formaldehyde, and blotted on to a Zeta-Probe GT membrane according to the manufacturer's instructions. Hybridization and washing were performed as described previously in DNA gel blot analyses (Park et al. 2009).

$\mathrm{Ca}^{2+}$ and other mineral analysis

The tobacco leaves and tomato fruits were dried at $70{ }^{\circ} \mathrm{C}$ for $4 \mathrm{~d}$. A total of $0.5 \mathrm{~g}$ (dry weight) of fruits was digested for analysis as described (Park et al. 2005a). Calcium content per gram of dry weight was determined by inductively coupled plasma emission spectrophotometry (Spectro, Kleve, Germany).

\section{Results}

\section{Generation of $s C A X 1-, C R T$-, and $s C A X 1-$ and $C R T$-co-expressing tobacco and}

\section{tomato plants}

The temporal and spatial regulation of $\mathrm{s} C A X 1$ is crucial for proper modulation of $\mathrm{Ca}^{2+}$ with plant cells (Park et al. 2005a). The 35S promoter confers strong constitutive expression in plants, and is often used to give high level expression of a given gene (Benfey et al. 1990). In previous studies, various $s C A X 1$-expressing lines under the control of the $35 \mathrm{~S}$ promoter showed symptoms similar to $\mathrm{Ca}^{2+}$ deficiency (Hirschi 1999; Park et al. 2005a), and this promoter may therefore be used effectively to 
1 identify the capacity to regulate $\mathrm{Ca}^{2+}$-related cellular dysfunction in

$2 s C A X 1$-expressing plants through manipulation of CRT. Initially $18 s C A X 1-$ and 20

$3 C R T$ - expressing lines were generated, respectively, and then we co-transformed $C R T$

4 into two independent $s C A X 1$-expressing T2 homozygous tobacco lines (sCAX1-1 and

5 sCAX1-2). The stable integration of the $35 S:: s C A X 1$ chimeric construct in the

6 genome of tobacco plants that were used for $C R T$ co-transformation was confirmed by

7 Southern-blot analysis (Fig. 1b). The line we termed sCAX1-2 appeared to contain a

8 single-copy insertion, while line sCAX1-1 and sCAX1-5 had more than one

$9 \quad$ integration event (Fig. 1b). Twenty independent $s C A X 1$ - and $C R T$-co-expressing tobacco lines (hereafter as $s C A X 1+C R T$ ) were generated by $C R T$ co-transformation.

11 Expression of $s C A X 1$ and $C R T$ transcripts were measured in T1 transgenic lines by RNA gel blot analysis. Two $s C A X 1$ - and $C R T$-co-expressing lines sCAX1+CRT-2 and -3 appeared to show stronger bands compared to other lines sCAX1+CRT-13, sCAX1-1, or CRT-1 (Fig 1c). The intensity of the signal in sCAX1+CRT-2 and -3 may result from high-level of expression in those particular lines by transformation variability, various technical issues such as an excess of loaded total RNAs, or the possible co-transformation effect of two different genes. Regardless, the results suggest that $s C A X 1$ and $C R T$ transcripts were expressed only in the SCAX1 and CRT transgenic lines, respectively; while both $s C A X 1$ and $C R T$ transcripts accumulated in the sCAX1+CRT-2, -3 , and -13 transgenic lines (Fig 1c). burning and the development of distinct necrotic lesions in the distal portion of fruits 
1 (BER). Thus, we were interested in determining whether co-expression of $C R T$ in

$2 s C A X 1$-expressing tomato plants would alleviate the symptoms. Initially $24 s C A X 1$ -

3 and $15 C R T$ - expressing lines were generated, respectively, and then we

4 co-transformed $C R T$ into a $s C A X 1$-expressing - 13 (a single-copy insertion) T2

5 homozygous tomato line that showed severe $\mathrm{Ca}^{2+}$ deficiency-like symptoms including

6 BER (data not shown). Twelve independent $s C A X 1+C R T$-expressing tomato lines

7 were generated. Two of each $s C A X 1-2$ and 13, CRT-9 and 21, and $s C A X 1+C R T-4$ and

85 expressing transgenic lines were randomly selected and confirmed by Southern-blot

9 and PCR analysis (Fig. 1d,e).

The stable integration of the $C R T$ in the genome was confirmed by Southern-blot

11 (Fig. 1d). We found a background band in every line, including wild-type, which might be caused by the endogenous $C R T$ in the tomato genome. The Southern-blot result suggests that the CRT-21, sCAX1+CRT-4, and sCAX1+CRT-5 lines contained a single-copy of CRT, while CRT-9 line contained 3 copies of CRT. The integration of

$15 s C A X 1$ in the genome was confirmed by PCR using sCAX1 primers (Fig. 1e,

Supplementary Table 1). The expression of $C R T$ and $s C A X 1$ was confirmed by 1). All the molecular works were conducted using the $\mathrm{T} 2$ generation plants.

CRT suppresses $s C A X 1$-induced $\mathrm{Ca}^{2+}$ deficiency-like symptoms of tobacco and

As shown previously (Hirschi 1999), sCAX1-expressing tobacco lines including two 
1 independent $s C A X 1$-expressing T2 homozygous tobacco lines (sCAX1-1 and

2 sCAX1-2, Fig. 2a, b) that were used for $C R T$ co-transformation have altered

3 morphology and growth characteristics. All the $s C A X 1$-expressing lines displayed

4 necrosis on the tips of the new leaves from a young stage, which is a $\mathrm{Ca}^{2+}$

5 deficiency-like symptom (Fig. 2c). In addition to the necrosis, all the

$6 s C A X 1$-expressing tobacco plants showed severe stunting (Fig. 3a, bottom). In

7 contrast, after introducing the $C R T$ into $s C A X 1$-expressing tobacco plants, the

8 symptoms were alleviated (Fig. $2 \mathrm{~d}$ and 3a, top).

To establish that the growth phenotypes were due to co-expression of the $C R T$,

40-45 each of $s C A X 1+C R T$-expressing T2 generation plants from 5 independent lines

11 (sCAX1+CRT-2, -3, -6, -13, and -27) were analyzed to determine if $C R T$ segregated with the robust growth phenotype. As shown in Fig. $3 b$ (right) and 3c, 4 of 5 lines showed a segregation pattern of 3:1 for the robust growth phenotype (Supplementary Table 2), and all the $C R T$-co-expressing lines were healthy while the absence of $C R T$ caused the reappearance of the symptoms associated with $s C A X 1$-expression [Fig. $3 \mathrm{~b}$ (left) and 3c]. This result suggests that CRT contributes to the recovering of

$17 s C A X 1$-expressing tobacco plants with $\mathrm{Ca}^{2+}$ deficiency-like symptoms. concentration in the cells, we measured the total accumulation of $\mathrm{Ca}^{2+}$ in the tobacco leaves in T2 generation transgenic plants. As shown in Fig. 3d, $s C A X 1$ - and $s C A X 1+C R T$-expressing tobacco plants accumulated significantly more (up to $25 \%$ )

$\mathrm{Ca}^{2+}$ than wild-type plants; however, $C R T$-expressing tobacco plants did not 
1 significantly enhance $\mathrm{Ca}^{2+}$ accumulation as compared with wild-type plants. In

2 addition, expression of $s C A X 1, C R T$ or $s C A X 1+C R T$ did not affect the accumulation

3 of other minerals $\left(\mathrm{Cu}^{2+}, \mathrm{Fe}^{2+}, \mathrm{Mg}^{2+}, \mathrm{Mn}^{2+}\right.$, and $\mathrm{Zn}^{2+}$, Supplementary Fig. 1). In order to ascertain whether CRT can suppress $s C A X 1$-induced adverse symptoms in tomato plants, we introduced $C R T$ into $s C A X 1$-expressing tomato plants.

6 As shown in Fig. 4a and Supplementary Fig. 2, the necrosis in leaf tips caused by

$7 \quad s C A X 1$-expressing was alleviated by the co-expression of $C R T$. Furthermore, when we

8 counted the number of the BER and healthy fruits of wild-type, $s C A X 1-, C R T$-, and

$9 \quad s C A X 1+C R T$-expressing $\mathrm{T} 2$ generation transgenic plants, respectively, the results

10 showed that the BER ratio could be reduced by introducing $C R T$ to the

$11 s C A X 1$-expressing plants. Although the ratio of BER in $s C A X 1+C R T$-expressing plants was not statistically different from that of $s C A X 1$-expressing plants, because the BER ratio shows a large variation among different plants even in the same line, the BER symptom in $s C A X 1+C R T$-expressing plants was indeed less severe than that in $s C A X 1$-expressing plants according to our day-to-day observation (Fig. 4b, c, and data not shown).

To determine how the co-expression of $C R T$ in sCAX1-expressing tomato alters $\mathrm{Ca}^{2+}$ concentration in the fruit cells, the total accumulation of $\mathrm{Ca}^{2+}$ in the tomato fruits of wild-type, $s C A X 1$-, $C R T$-, and $s C A X 1+C R T$-expressing T2 generation plants was analyzed. All the $s C A X 1-$ and $s C A X 1+C R T$-expressing tomatoes showed

21 significantly higher $\mathrm{Ca}^{2+}$ content than wild-type tomatoes (Fig. 4d). However, among $15 C R T$ - expressing tomato lines, the majority of these lines did not significantly 
1 enhance $\mathrm{Ca}^{2+}$ content as compared to wild-type tomatoes while the fruits of line \#9

2 and \#21 increased $\sim 9 \%$ and $\sim 40 \%$ more $\mathrm{Ca}^{2+}$ than wild-type fruits, respectively (Fig.

$34 d)$.

5 CRT suppresses $s C A X 1$-induced ion sensitivity in tobacco lines under ion imbalance growth condition

7 We further tested whether introducing CRT could mitigate the ion sensitivity caused by sCAX1. After in vitro growing lines on standard MS media for $14 \mathrm{~d}$, wild-type and transgenic seedlings (sCAX1-1 and -2; CRT-1; sCAX1+CRT-2, -3, -6, -13, and -27) were transferred to media containing various concentrations of $\mathrm{Mg}^{2+}$ or $\mathrm{K}^{+}$, or reduced $\mathrm{Ca}^{2+}$. All the $s C A X 1$-expressing seedlings were sensitive to the ion imbalance that failed to perturb the growth of wild-type and $s C A X 1+C R T$-expressing plants. For example, after being transferred in the $\mathrm{Ca}^{2+}$-depleted media, the $s C A X 1$-expressing seedlings could not grow and develop leaves (Fig. 5a). In contrast, the $s C A X 1+C R T$-expressing seedlings grew vigorously without any abnormal morphological developments (Fig. 5a). In the medium containing $50 \mathrm{mM} \mathrm{MgCl}$, the sCAX1-expressing seedlings also showed hypersensitivity to the stress, such as necrotic lesions in the young leaves and stunted growth (Fig. 5b); however, the $s C A X 1+C R T$-expressing seedlings did not display any adverse growth (Fig. 5b). The sensitivity of $s C A X 1$-expressing tobacco to $\mathrm{K}^{+}$salt stress was not as severe as the $\mathrm{Ca}^{2+}$ or $\mathrm{Mg}^{2+}$ growth phenotypes. However, after transferring the seedlings to the media containing $100 \mathrm{mM} \mathrm{KCl}$ for 60 days, the necrotic lesions displayed on the 
$1 s C A X 1$-expressing leaf tips, but not on the leaves of $s C A X 1+C R T$-expressing plants

2 (Fig. 5c).

3

4 Discussion

6 Conventional breeding strategies for mineral biofortification of crops rely on

7 germplasm with limited genetic variation for many traits (White and Broadley 2009).

8 In some cases, genetic diversity can be increased by crossing to distant related species

9 and movement of the traits slowly into the agronomically useful cultivars. However, the variation in a trait, in particular $\mathrm{Ca}^{2+}$ concentration, may not cover the range

11 desired for agronomic value. Thus, breeders may not have the appropriate level of

12 genetic variation in $\mathrm{Ca}^{2+}$ concentration among varieties. Our genetic engineering

13 approach allows over-expression of $\mathrm{Ca}^{2+}$ transporter genes and expression to a level

14 not present in germplasm. However, a major impediment for the development of

$\mathrm{Ca}^{2+}$-biofortified crops using $\mathrm{Ca}^{2+}$ transporters is that the transgenic lines expressing

$s C A X 1$ dramatically increase $\mathrm{Ca}^{2+}$ content in their tissues, but also display severe $\mathrm{Ca}^{2+}$ deficiency-like symptoms, leading to significant yield losses (Hirschi 1999; Park et al.

18 2005a). Previous studies in Arabidopsis suggest that CRT plays a key role in the regulation of $\mathrm{Ca}^{2+}$ status of the plant $\mathrm{ER}$ and that the $\mathrm{ER}$, in addition to the vacuole, is

20 an important $\mathrm{Ca}^{2+}$ store in plant cells (Persson et al. 2001). In fact, Arabidopsis

21 plants over-expressing a version of CRT contained up to $35 \%$ more total $\mathrm{Ca}^{2+}$, and the 22 increased $\mathrm{Ca}^{2+}$ sequestered by the CRT appeared to benefit plants when grown in a 
$1 \mathrm{Ca}^{2+}$ deficient situation (Wyatt et al. 2002). Results from these studies also suggest

2 that the CRT-mediated alteration of the $\mathrm{ER} \mathrm{Ca}^{2+}$ pool could potentially make $\mathrm{Ca}^{2+}$

3 more readily accessible for release into the cytosol and further strengthens the notion

4 that the increased $\mathrm{Ca}^{2+}$-buffering capacity generated by overproduction of CRT helps

5 maintain $\mathrm{Ca}^{2+}$ homeostasis.

6 There are at least two different groups of CRT isoforms, CRT1/CRT2 and CRT3,

7 in higher plants (Persson et al. 2003). Different isoforms of CRT exhibit differences in

8 the tissue-specific and stress-dependent expression patterns, indicating that they are

9 involved in different pathways for their functions in plants (Jia et al. 2009). Among

10 different CRT isoforms, CRT1 can substitute for animal CRTs in terms of modulation

11 of $\mathrm{Ca}^{2+}$ homeostasis (Christensen et al. 2008). In addition, the role of maize CRT1 in

12 plant responses to stress has been previously studied (Wyatt et al. 2002; Akesson et al.

13 2005). Thus, a maize CRT1 was chosen in this study to further investigate whether

14 co-expression of the $C R T 1$ may mitigate the $\mathrm{Ca}^{2+}$ deficiency-like symptoms caused by

15 expression of $s C A X 1$. Indeed, co-expression of a maize $C R T$ mitigates the $\mathrm{Ca}^{2+}$

16 deficiency-like symptoms including tip burning and BER (Figs. 2, 3, and 4) and the

17 hypersensitivity to ion imbalance (Fig. 5) caused by expression of $s C A X 1$ in tobacco

18 and tomato plants. Although $C R T$ expression alone was not sufficient to dramatically

19 alter the $\mathrm{Ca}^{2+}$ content and incidence of BER in this study, our results here suggest that

20 combining expression of transporters and binding proteins may be a strategy to alter

21 the concentration of $\mathrm{Ca}^{2+}$ without negatively impacting plant growth and

22 development. 
CRT is also known to harbor chaperone-like functions that may influence protein

2 folding by interacting with unfolded proteins (Crofts and Denecke 1998). Indeed,

3 recent studies indicate that AtCRT1a (also known as AtCRT1) and CRT1b family

4 members are components of a general ER chaperone network and AtCRT1a restores

5 putative folding deficiencies (Christensen et al., 2008; 2010). Furthermore, CRT

expression is induced by biotic and abiotic stresses and may ensure plants adapt to

7 various stresses (Jia et al., 2009). Therefore, it cannot be ruled out that co-expression

8 of $C R T$ in $s C A X 1$-expressing lines could mitigate adverse effects by working as a

9 stress-inducible chaperone and/or a positive regulator in stress responses.

Most mature plant cells have a central vacuole, which often takes up more

11 than $80 \%$ of the cell volume (Martinoia et al. 2000). The vacuole is considered to be the largest intracellular storage compartment for $\mathrm{Ca}^{2+}$ (Gelli and Blumwald 1993), and

13 fluxes of $\mathrm{Ca}^{2+}$ across the vacuole are similar in magnitude to those occurring across the plasma membrane (Bush 1995). The plant ER, like the vacuole, is thought to 15 function as a substantial $\mathrm{Ca}^{2+}$ storage compartment (Iwano et al. 2009). In animals, total $\mathrm{Ca}^{2+}$ concentration can approach micromolar concentrations in the mammalian sarcoplasmic reticulum (SR) (Zucchi and RoncaTestoni 1997). Measurements of $\mathrm{Ca}^{2+}$

18 efflux from plant ER vesicles indicate that there is rapid exchange of $\mathrm{Ca}^{2+}$ across the ER (White and Broadley 2003). Our data suggest that increased expression of $\mathrm{Ca}^{2+}$ binding proteins on the ER can ameliorate the adverse effects caused by increasing

21 sequestration of $\mathrm{Ca}^{2+}$ into the vacuoles. Recent technological advances should enable 22 future studies to make a detailed analysis of $\mathrm{Ca}^{2+}$ dynamics in different cellular 
1 compartments to decipher the temporal and spatial characteristics of $\mathrm{Ca}^{2+}$ signatures

2 caused by altered $s C A X 1$ and $C R T$ expression (Krebs et al. 2012).

In Arabidopsis mutants where CAX activity is greatly reduced, the lines show 3-fold more apoplastic $\mathrm{Ca}^{2+}$ (Conn et al. 2011). On the other hand, when $s C A X 1$ expression is increased in tomato plants, apoplastic concentration of $\mathrm{Ca}^{2+}$ are reduced (de Freitas et al. 2011). Depleting the apoplastic $\mathrm{Ca}^{2+}$ pool by expression of $s C A X 1$ may cause the $\mathrm{Ca}^{2+}$ deficiency-like symptoms. One of the important functions of apoplastic $\mathrm{Ca}^{2+}$ is cross-linking the homogalacturonans for the biosynthesis of cell wall (Cosgrove 2005). Thus, reducing the apoplastic $\mathrm{Ca}^{2+}$ concentration in $s C A X 1$-expressing plants could disrupt the cell wall biosynthesis and further results in growth stunting, tip burning and BER, especially in the tissues that the cell division and wall formation are most rapid (Figs. 2, 3 and 4). Furthermore, recent studies show that suppressing expression of pectin methylesterases (PMES) in tomato fruit reduces the amount of $\mathrm{Ca}^{2+}$ bound to the cell wall, subsequently increasing $\mathrm{Ca}^{2+}$ available for other cellular functions and, thereby, reducing fruit susceptibility to BER(de Freitas et al. 2012). Therefore, future research may focus on elucidating the effects of co-expression of $C R T$ and $s C A X 1$ on the distribution/partitioning of symplastic and apoplastic $\mathrm{Ca}^{2+}$. $\mathrm{Ca}^{2+}$ disorders, likely involving altered CAX activity, may be responsible for losses in crop production (Ho and White 2005). These putative $\mathrm{Ca}^{2+}$ disorders have been thought to develop similarly (White and Broadley 2003) and to be associated with a $\mathrm{Ca}^{2+}$ deficiency within the cells (Saure 2001). BER in tomato and bitter pit in 
1 apples may also be linked to changes in CAX activity (Park et al. 2005a; de Freitas et

2 al. 2010). To explain the primary causes of BER, two hypotheses have been

3 considered, 1) $\mathrm{Ca}^{2+}$ deficiency and 2) aberrant $\mathrm{Ca}^{2+}$ homeostasis. The majority of

4 studies on BER in recent years have proposed that $\mathrm{Ca}^{2+}$ imbalance events at the

5 cellular level, triggered by environmental stresses, may result in aberrant intracellular

$6 \mathrm{Ca}^{2+}$ signals, ultimately leading to BER. It is suggested that this phenomenon might

7 be a consequence of aberrant cytosolic $\mathrm{Ca}^{2+}$ regulation, and therefore spatial and

8 temporal control of cellular $\mathrm{Ca}^{2+}$ concentration is a key factor determining incidence

9 of $\mathrm{Ca}^{2+}$-related physiological disorders (Hirschi 2004; Ho and White 2005; Park et al.

10 2005a; Karley and White 2009; White and Broadley 2009; Dayod et al. 2010; de

11 Freitas et al. 2011). Regardless of mechanisms, our work here shows that elevated

12 expression of $C R T$ can reduce the severity of growth abnormalities caused by

13 increased CAX activity.

Utilization of the $s C A X 1$ for $\mathrm{Ca}^{2+}$ biofortification have been extensively investigated in various horticultural crop species (carrot, potato, tomato, lettuce) since the expression of $s C A X 1$ can dramatically improve the $\mathrm{Ca}^{2+}$ accumulation in their

17 edible tissues (Hirschi 1999; Park et al. 2004; Park et al. 2005a; Park et al. 2005b;

18 Park et al. 2008; Park et al. 2009). Interestingly, not all the increased $\mathrm{Ca}^{2+}$ in the 19 transporter-modified carrots was bioavailable (Morris et al. 2008). This may be due 20 to a fraction of the extra $\mathrm{Ca}^{2+}$ being bound to antinutrients within the carrot (Hirschi

21 2009). This serves as a cautionary example for scientists that assume that all increases in nutrient content directly equate to increased bioavailability. However, the 
1 modified carrots are a better source of $\mathrm{Ca}^{2+}$ because total $\mathrm{Ca}^{2+}$ absorbed was higher.

2 Although we postulate that the $\mathrm{Ca}^{2+}$ content has increased within the vacuoles of the

3 modified carrots, we have not yet addressed the intracellular $\mathrm{Ca}^{2+}$ redistribution in

4 these plants experimentally. We postulate that co-expressing various transporters and

$5 \quad C R T s$ will differentially increase total $\mathrm{Ca}^{2+}$ content and the fractional absorption of

$6 \mathrm{Ca}^{2+}$ in animals. However, feeding studies must be conducted to address the

7 bioavailability issues in the double transformants, including the CRT+sCAX1

8 transformed crops.

Our working hypothesis is that the $\mathrm{Ca}^{2+}$ content within these double transgenic plants is more evenly distributed throughout the plant cells. However, in order to decode the relationship between expression of transporters and binding proteins and location of $\mathrm{Ca}^{2+}$ within the cell, we must determine the spatial resolution of $\mathrm{Ca}^{2+}$ within the plant (Punshon et al. 2009; Conn et al. 2011; Punshon et al. 2012). Various techniques exist to visualize the distribution and abundance of elements within plants. These techniques are useful because, in contrast with bulk or volume-averaged measures (such as inductively coupled plasma mass spectroscopy, ICP-MS) where the sample is homogenized, the confinement of elements within specific plant organs, tissues, cells and even organelles can be seen (Punshon et al. 2012). The potential of synchrotron x-rays in spatially resolved elemental imaging in plants has begun to be realized (Punshon et al. 2009). In fact, this work has recently been done to demonstrate the alterations of $\mathrm{Ca}^{2+}$ partitioning in seeds of Arabidopsis lines altered in CAX expression (Punshon et al. 2012), it will certainly be interesting to apply this 
technology to the edible portions of crops co-expressing both $s C A X 1$ and $C R T$.

$$
\text { In conclusion, while genetic engineering strategies to increase } \mathrm{Ca}^{2+} \text { content by }
$$

expression of a single gene (either $s C A X 1$ or $C R T$ ) alone have provided promising

results, co-expressing of $C R T$ and $s C A X 1$ enhances the $\mathrm{Ca}^{2+}$ content of plants without any apparent detrimental effects potentially caused by sCAX1 expression.

Manipulation of the partitioning of nutrients across various endomembranes may be a means to increase plant nutrient content while maintaining crop productivity.

\section{Acknowledgements}

This research was supported by the Kansas State University AES project NAHF381121 (to SHP), the NIHHS RDA-KSU Cooperative Research Project (JSH) and the Technology Development Program for Agriculture and Forestry, Ministry of Agriculture and Forestry, Republic of Korea (CKK). We thank Dr. Wendy Boss for her inspiration and Dr. Staffan Persson (Max-Planck-Institute, Germany) for supplying the $\mathrm{pE} 1775:$ CRT expression vector.

\section{References}

Akesson A, Persson S, Love J, Boss WF, Widell S, Sommarin M (2005)

Overexpression of the $\mathrm{Ca}^{2+}$-binding protein calreticulin in the endoplasmic reticulum improves growth of tobacco cell suspensions (Nicotiana tabacum) in 
Bachrach LK (2001) Acquisition of optimal bone mass in childhood and adolescence. Trends Endocrin Met 12: 22-28

Benfey PN, Ren L, Chua NH (1990) Tissue-specific expression from CaMV 35S-enhancer subdomains in early stages of plant development. EMBO J 9: $1677-1684$

Bush DS (1995) Calcium regulation in plant cells and its role in signaling. Annu Rev Plant Physiol Plant Mol Biol 46: 95-122

Christensen A, Svensson K, Persson S, Michalak M, Jung J, Michalak M, Widell S, Sommarin M (2008) Functional characterization of Arabidopsis Calreticulin1a; a key alleviator of endoplasmic reticulum stress. Plant Cell Physiol 49: 912-924

Christensen A, Svensson K, Thelin L, Zhang W, Tintor N, Prins D, Funke N, Michalak M, Schulze-Lefert P, Saijo Y, Sommarin M, Widell S, Persson S (2010) Higher plant calreticulins have acquired specialized functions in Arabidopsis. PLoS ONE 5: e11342

Conn SJ, Gilliham M, Athman A, Schreiber AW, Baumann U, Moller I, Cheng NH, Stancombe MA, Hirschi KD, Webb AAR, Burton R, Kaiser BN, Tyerman SD, Leigh RA (2011) Cell-specific vacuolar calcium storage mediated by CAX1 regulates apoplastic calcium concentration, gas exchange, and plant productivity in Arabidopsis. Plant Cell 23: 240-257

Cosgrove DJ (2005) Growth of the plant cell wall. Nat Rev Mol Cell Bio 6: 850-861 
1 Crofts A, Denecke J (1998) Calreticulin and calnexin in plants. Trends Plant Sci 3: 396

Dayod M, Tyerman SD, Leigh RA, Gilliham M (2010) Calcium storage in plants and the implications for calcium biofortification. Protoplasma 247: 215-231

de Freitas S, Handa AK, Wu Q, Park S, Mitcham EJ (2012) Role of pectin methylesterases in cellular calcium distribution and blossom-end rot development in tomato fruit. Plant J DOI: 10.1111/j.1365-313X.2012.05034.X

de Freitas ST, do Amarante CVT, Labavitch JM, Mitcham EJ (2010) Cellular approach to understand bitter pit development in apple fruit. Postharvest Biol Tech 57: 6-13

de Freitas ST, Padda M, Wu QY, Park S, Mitcham EJ (2011) Dynamic alternations in cellular and molecular components during blossom-end rot development in tomatoes expressing $s C A X 1$, a constitutively active $\mathrm{Ca}^{2+} / \mathrm{H}^{+}$antiporter from Arabidopsis. Plant Physiol 156: 844-855

Gelli A, Blumwald E (1993) Calcium retrieval from vacuolar pools - characterization of a vacuolar calcium-channel. Plant Physiol 102: 36-36

Hirschi KD (1999) Expression of Arabidopsis CAX1 in tobacco: Altered calcium homeostasis and increased stress sensitivity. Plant Cell 11: 2113-2122

Hirschi KD (2004) The calcium conundrum. Both versatile nutrient and specific signal. Plant Physiol 136: 2438-2442

Hirschi KD (2009) Nutrient Biofortification of Food Crops. Annu Rev Nutr 29: $401-421$ 
1 Hirschi KD, Zhen RG, Cunningham KW, Rea PA, Fink GR (1996) CAX1, an $\mathrm{H}^{+} / \mathrm{Ca}^{2+}$ antiporter from Arabidopsis. Proc Nat Acad Sci USA 93: 8782-8786

Ho LC, White PJ (2005) A cellular hypothesis for the induction of blossom-end rot in tomato fruit. Ann Bot 95: 571-581

Hoekema A, Hirsch PR, Hooykaas PJJ, Schilperoort RA (1983) A binary plant vector strategy based on separation of Vir-region and T-region of the Agrobacterium-tumefaciens Ti-Plasmid. Nature 303: 179-180

Holsters M, Dewaele D, Depicker A, Messens E, Vanmontagu M, Schell J (1978) Transfection and transformation of Agrobacterium-tumefaciens. Mol Gen Genet 163: 181-187

Horsch RB, Fry JE, Hoffmann NL, Eichholtz D, Rogers SG, Fraley RT (1985) A simple and general-method for transferring genes into plants. Science 227: $1229-1231$

Iwano M, Entani T, Shiba H, Kakita M, Nagai T, Mizuno H, Miyawaki A, Shoji T, Kubo K, Isogai A, Takayama S (2009) Fine-tuning of the cytoplasmic $\mathrm{Ca}^{2+}$ concentration is essential for pollen tube growth. Plant Physiol 150: $1322-1334$

Jia XY, He LH, Jing RL, Li RZ (2009) Calreticulin: conserved protein and diverse functions in plants. Physiol Plantarum 136: 127-138

Karley AJ, White PJ (2009) Moving cationic minerals to edible tissues: potassium, magnesium, calcium. Curr Opin Plant Biol 12: 291-298

Krebs M, Held K, Binder A, Hashimoto K, Den Herder G, Parniske M, Kudla J, 
Schumacher K (2012) FRET-based genetically encoded sensors allow high-resolution live cell imaging of $\mathrm{Ca}^{2+}$ dynamics. Plant J 69: 181-192

Lee LY, Kononov ME, Bassuner B, Frame BR, Wang K, Gelvin SB (2007) Novel plant transformation vectors containing the superpromoter. Plant Physiol 145: $1294-1300$

Martinoia E, Massonneau A, Frangne N (2000) Transport processes of solutes across the vacuolar membrane of higher plants. Plant Cell Physiol 41: 1175-1186

Mei H, Zhao J, Pittman JK, Lachmansingh J, Park S, Hirschi KD (2007) In planta regulation of the Arabidopsis $\mathrm{Ca}^{2+} / \mathrm{H}^{+}$antiporter CAX1. J Exp Bot 58: $3419-3427$

Morris J, Hawthorne KM, Hotze T, Abrams SA, Hirschi KD (2008) Nutritional impact of elevated calcium transport activity in carrots. Proc Nat Acad Sci USA 105: $1431-1435$

Murashige T, Skoog F (1962) A revised medium for rapid growth and bioassays with tobacco tissue cultures. Physiol Plantarum 15: 473-497

Park S, Cheng NH, Pittman JK, Yoo KS, Park J, Smith RH, Hirschi KD (2005a) Increased calcium levels and prolonged shelf life in tomatoes expressing Arabidopsis $\mathrm{H}^{+} / \mathrm{Ca}^{2+}$ transporters. Plant Physiol 139: 1194-1206

Park S, Elless MP, Park J, Jenkins A, Lim W, Chambers E, Hirschi KD (2009) Sensory analysis of calcium-biofortified lettuce. Plant Biotech J 7: 106-117

Park S, Elless MP, Park J, Lim W, Hirschi KD (2008) Genetic manipulation for enhancing calcium uptake in lettuce. In Vitro Cell Dev-An 44: S54-S55 
1 Park S, Kang TS, Kim CK, Han JS, Kim S, Smith RH, Pike LM, Hirschi KD (2005b) Genetic manipulation for enhancing calcium content in potato tuber. $\mathrm{J}$ Agr Food Chem 53: 5598-5603

Park S, Kim CK, Pike LM, Smith RH, Hirschi KD (2004) Increased calcium in carrots by expression of an Arabidopsis $\mathrm{H}^{+} / \mathrm{Ca}^{2+}$ transporter. Mol Breeding 14: $275-282$

Park S, Morris JL, Park JE, Hirschi KD, Smith RH (2003) Efficient and genotype-independent Agrobacterium - mediated tomato transformation. J Plant Physiol 160: 1253-1257

Park YD, Papp I, Moscone EA, Iglesias VA, Vaucheret H, Matzke AJM, Matzke MA (1996) Gene silencing mediated by promoter homology occurs at the level of transcription and results in meiotically heritable alterations in methylation and gene activity. Plant J 9: 183-194

Persson S, Wyatt SE, Love J, Thompson WF, Robertson D, Boss WF (2001) The Ca ${ }^{2+}$ status of the endoplasmic reticulum is altered by induction of calreticulin expression in transgenic plants. Plant Physiol 126: 1092-1104

Persson S, Rosenquist M, Svensson K, Galvao R, Boss W, Sommarin M (2003) Phylogenic analyses and expression studies reveal two distinct groups of calreticulin isoforms in higher plants. Plant Physiol 133: 1385-1396

Pittman JK, Hirschi KD (2001) Regulation of CAX1, an Arabidopsis $\mathrm{Ca}^{2+} / \mathrm{H}^{+}$ antiporter. Identification of an N-terminal autoinhibitory domain. Plant Physiol 127: $1020-1029$ 
1 Pittman JK, Hirschi KD (2003) Don't shoot the (second) messenger: endomembrane transporters and binding proteins modulate cytosolic $\mathrm{Ca}^{2+}$ levels. Curr Opin Plant Biol 6: 257-262

Punshon T, Guerinot ML, Lanzirotti A (2009) Using synchrotron X-ray fluorescence microprobes in the study of metal homeostasis in plants. Ann Bot 103: $665-672$

Punshon T, Hirschi K, Yang J, Lanzirotti A, Lai B, Guerinot ML (2012) The Role of CAX1 and CAX3 in elemental distribution and abundance in Arabidopsis Seed. Plant Physiol 158: 352-362

Saure MC (2001) Blossom-end rot of tomato (Lycopersicon esculentum Mill.) - a calcium- or a stress-related disorder? Sci Hortic 90: 193-208

White PJ, Broadley MR (2003) Calcium in plants. Ann Bot 92: 487-511

White PJ, Broadley MR (2009) Biofortification of crops with seven mineral elements often lacking in human diets - iron, zinc, copper, calcium, magnesium, selenium and iodine. New Phytol 182: 49-84

Wyatt SE, Tsou PL, Robertson D (2002) Expression of the high capacity calcium-binding domain of calreticulin increases bioavailable calcium stores in plants. Transgenic Res 11: 1-10

Zhao J, Connorton JM, Guo YQ, Li XK, Shigaki T, Hirschi KD, Pittman JK (2009) Functional Studies of Split Arabidopsis $\mathrm{Ca}^{2+} / \mathrm{H}^{+}$Exchangers. J Biol Chem 284: $34075-34083$

Zucchi R, RoncaTestoni S (1997) The sarcoplasmic reticulum $\mathrm{Ca}^{2+}$ channel/ryanodine 

receptor: Modulation by endogenous effectors, drugs and disease states. Pharmacol Rev 49: 1-51

3 


\section{$1 \quad$ Figures}

(A) pCAMV35S::sCAX1

\begin{tabular}{|l|l|l|l|l|}
\hline Nos Pro & Kan R & Nos Term \\
\hline
\end{tabular} \begin{tabular}{|l|l|l|l|} 
35S Pro & sCAX1 & Nos Term \\
\hline & & & \\
\hline
\end{tabular}

PE1775::CRT
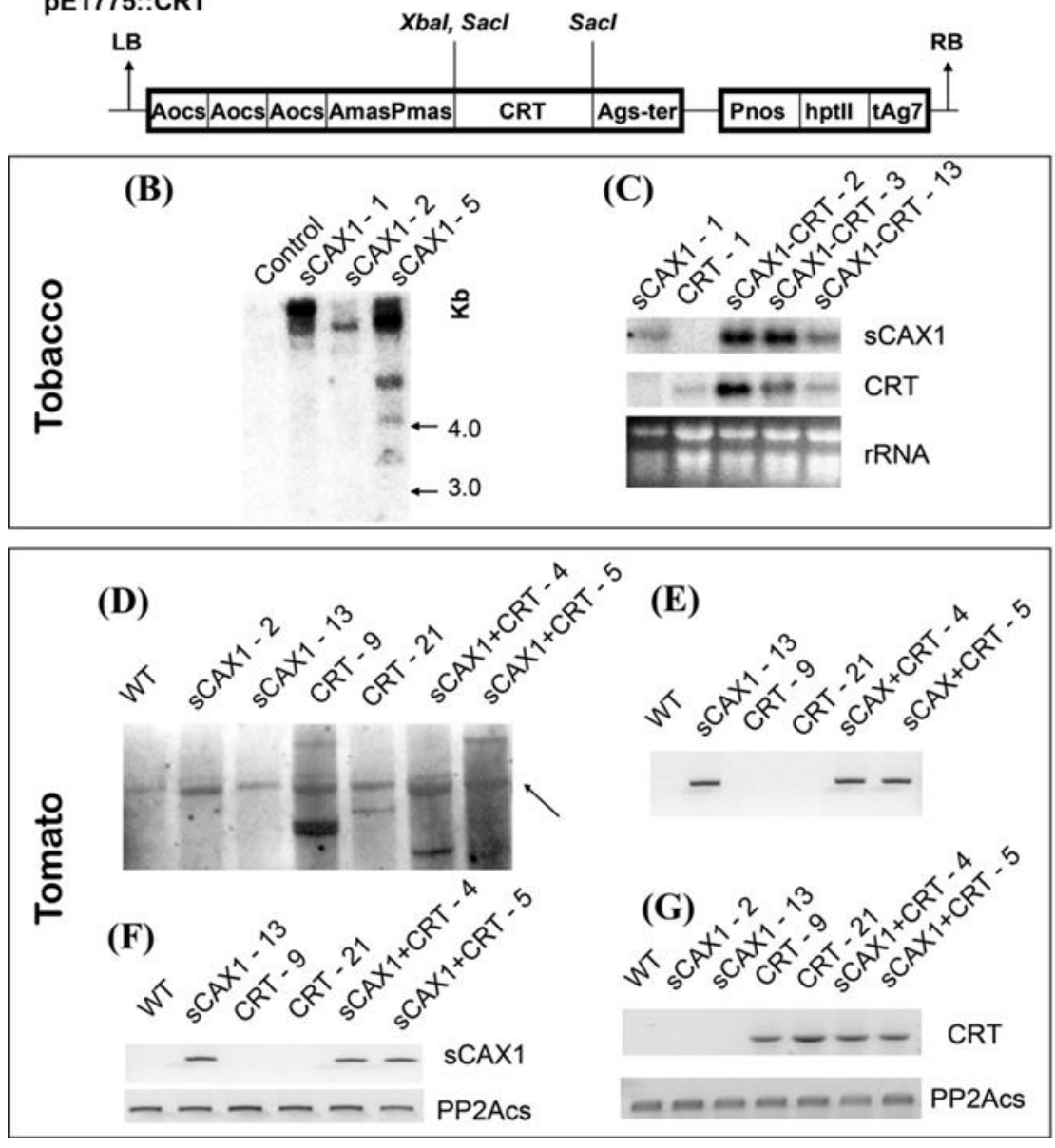

3 Fig. 1 Molecular analyses of $s C A X 1-, C R T$ - and $s C A X 1+C R T$-expressing tobacco and

4 tomato plants. (a) T-DNA regions of pCaMV35S::sCAX1 and pE1775::CRT. RB,

5 Right border; LB, left border; Nos-pro, nopaline synthase promoter, Kan R, the gene

6 conferring resistance to kanamycin, neomycin phosphotransferase (NPTII); Nos-ter,

7 nopaline synthase terminator. $35 \mathrm{~S}$ pro, CaMV 35S promoter; sCAX1, short cut cation

8 exchanger 1 coding region; Aos, octopine synthase transcriptional activating element;

9 AmasPmas, mannopine synthase 2' activating and promoter elements; CRT, maize 
1 calreticulin coding region; ags-ter, polyA addition signal from the agropine synthase

2 gene. hptII, gene conferring resistance to hygromycin; Pnos, mopaline synthase

3 promoter; tAg7, poly A addition signal for T-DNA gene 7. (b) Southern-blot analysis

4 of transgenic tobacco plants. Ten micrograms of tobacco genomic DNA were digested

5 with $S a c I$, and hybridized with the $S C A X 1$ probe. (c) Northern-blot analysis of

6 transgenic tobacco plants. Ten micrograms of total RNA from leaves were hybridized

7 with $s C A X 1$ and $C R T$ probe, respectively. Ethidium bromide-strained rRNA (bottom)

8 is shown as a loading control. (d) Southern-blot analysis of transgenic tomato plants

9 with CRT probe. Ten micrograms of tomato genomic DNA were digested with XbaI,

10 and hybridized with $C R T$ probe. The arrow indicates the endogenous tomato $C R T$

11 gene that was detected by maize $C R T$ probe. (e) PCR detection of $s C A X 1$ in genomic

12 level. (f) RT-PCR detection of the expression of $s C A X 1$. (g) RT-PCR detection of the

13 expression of CRT. SIPP2Acs was used as tomato housekeeping gene.

14 

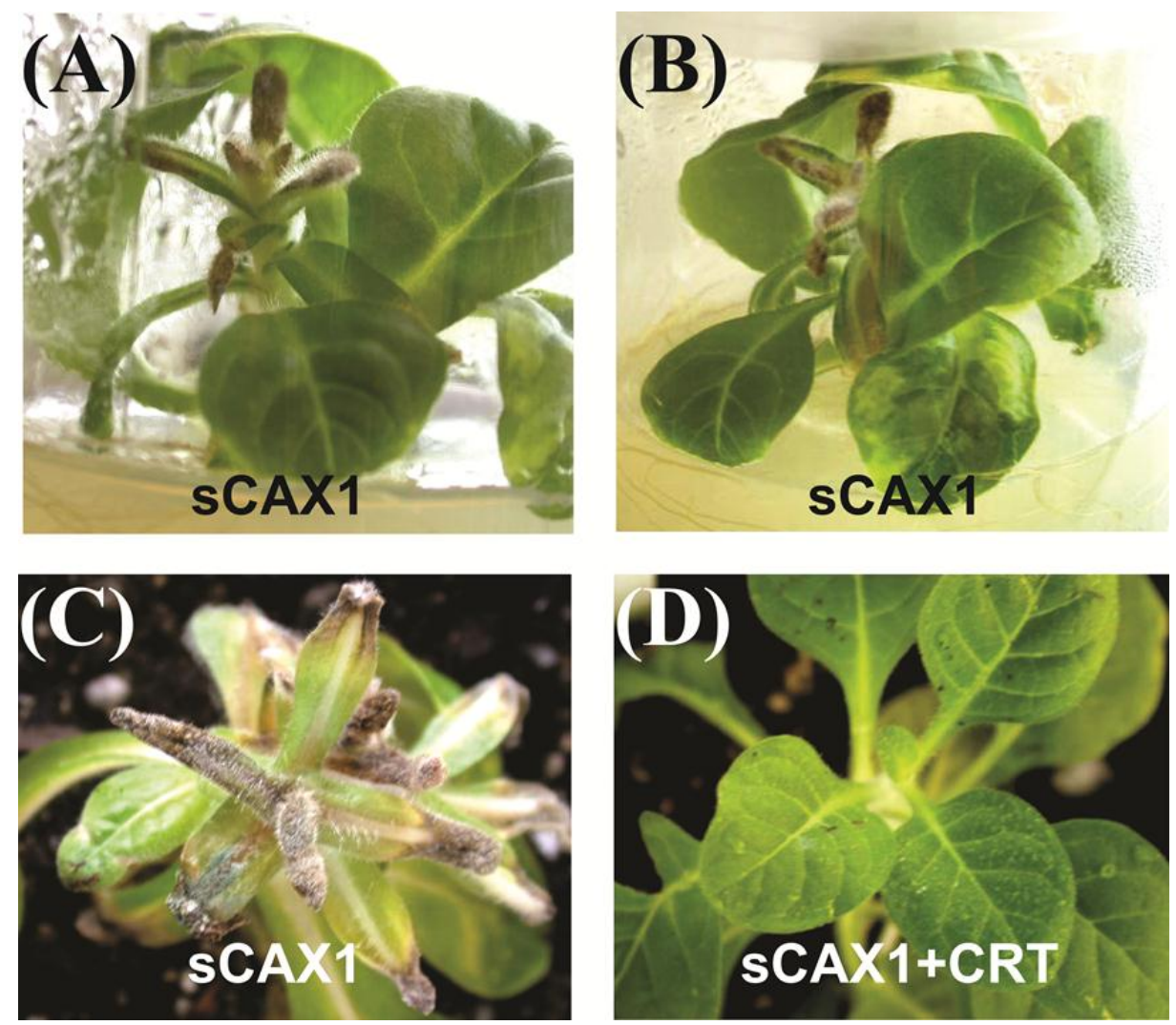

2 Fig. 2 Morphology of $s C A X 1$-, and $s C A X 1+C R T$-expressing tobacco plants at young

3 stage. (a-b) the $s C A X 1$-expressing tobacco plants used for $C R T$ transformation. (c) the

4 morphology of $s C A X 1$-expressing tobacco seedlings. (d) the morphology of

$5 \quad s C A X 1+C R T$-expressing tobacco seedlings.

6 


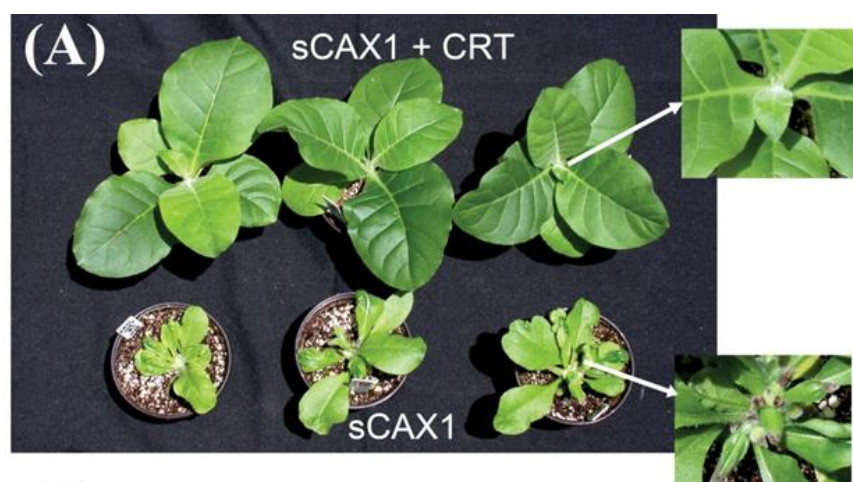

(B)
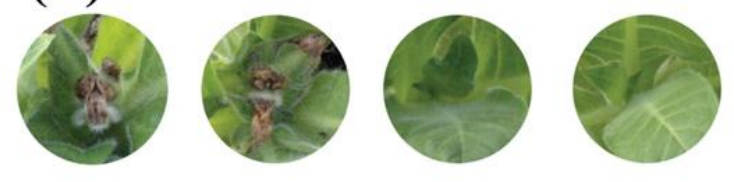

I

II

III

IV

T2 generation of $\mathrm{SCAX} 1+\mathrm{CRT}$

(C)

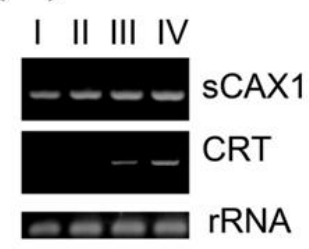

2 Fig. 3 Segregation of the $\mathrm{Ca}^{2+}$ deficiency-like symptoms. (a) Morphology of $\mathrm{T} 1$

3 generation of $s C A X 1$-, and $s C A X 1+C R T$-expressing tobacco plants. (b) Segregation of

4 the morphology in $\mathrm{T} 2$ generation of $s C A X 1+C R T$-expressing plants. Some of the

5 plants maintained the normal morphology, but some returned to the

$6 \mathrm{Ca}^{2+}$ deficiency-like symptoms. (c) Detection of the expression of $s C A X 1$ and $C R T$ in

$7 \quad \mathrm{~T} 2$ generation $s C A X 1+C R T$-expressing plants by RT-PCR. (d) $\mathrm{Ca}^{2+}$ concentration of

8 T2 generation tobacco leaves of different lines. All results shown here are the means

9 of 3 biological replicates, and the error bars indicate the standard deviations (S.D. $n=3$ )

$10 \quad$ (Student $\mathrm{t}$ test, $* \mathrm{p}<0.05, * * \mathrm{p}<0.01)$ 

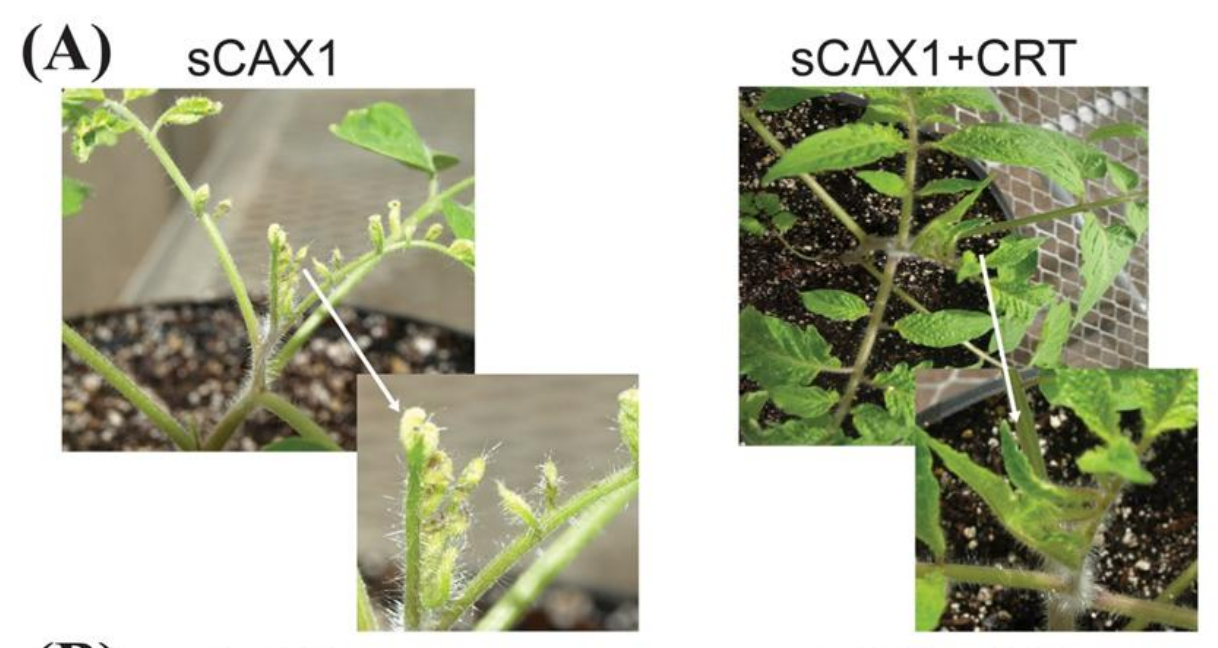

(B) $\mathrm{sCAX} 1$
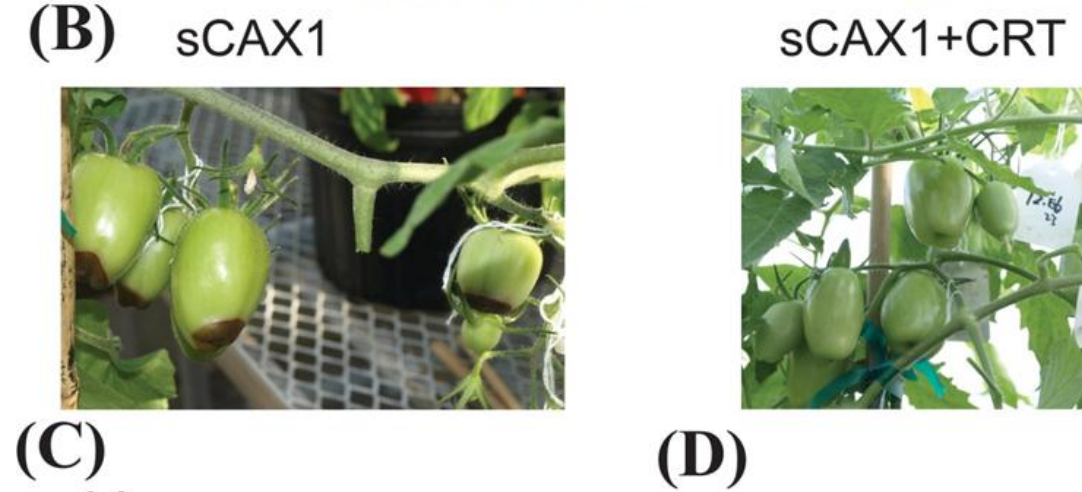

(D)
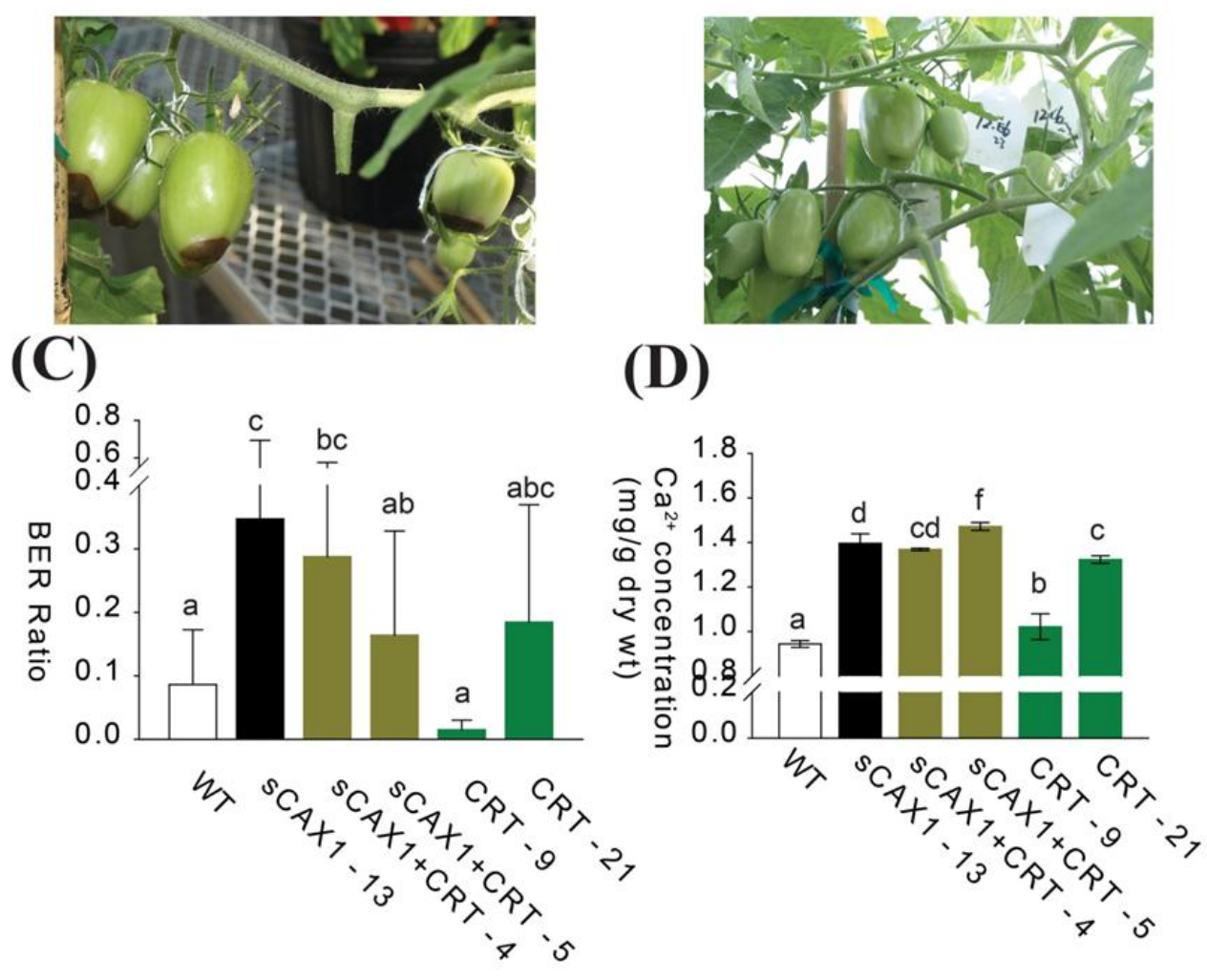

2 Fig. 4 Expression of $C R T$ mitigated the $\mathrm{Ca}^{2+}$ deficiency-like symptoms of

$3 s C A X 1$-expressing tomato plants. (a) Expression of CRT mitigated the leaf tip burning

4 of $s C A X 1$-expressing tomato plants. (b) Expression of $C R T$ reduced the BER

5 incidence of $s C A X 1$-expressing tomato plants. Left panel, $s C A X 1$-expressing tomato

6 plants; right panel, $s C A X 1+C R T$-expressing tomato plants. (c) BER ratio of wild-type,

$7 \quad s C A X 1-, C R T$-, and $s C A X 1+C R T$-expressing tomato plants. (d) Concentrations of 
$1 \mathrm{Ca}^{2+}$ in fruits of wild type, $s C A X 1-$, and $s C A X 1+C R T$-expressing tomato plants. All

2 results shown here are the means of 3 biological replicates, and the error bars indicate

3 the standard deviations (S.D. $n=3$ ). Means accompanied by the same letter are not

4 significantly different using ANOVA analysis $(\mathrm{p}<0.05)$.

(A)

\begin{tabular}{cr} 
Low $^{2} \mathrm{Ca}^{2+}$ & 30-day-old \\
\hline sCAX1+CRT - $2 \quad$ SCAX1-1
\end{tabular}
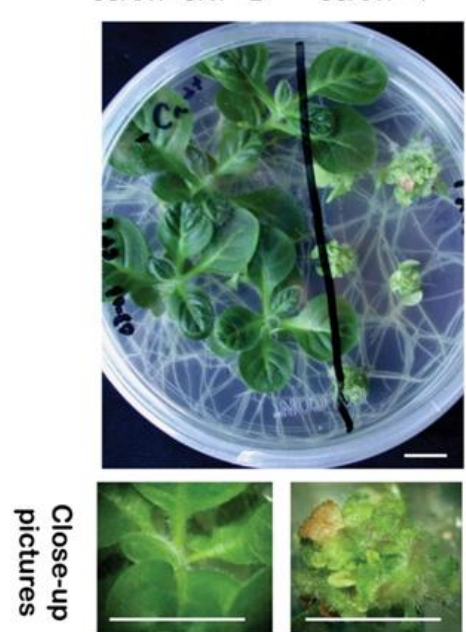

7

8

9
(B)

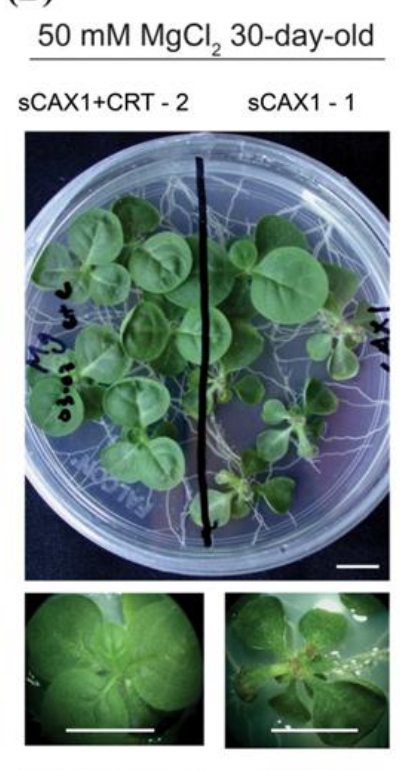

SCAX1+CRT - $2 \quad$ SCAX1-1
(C)

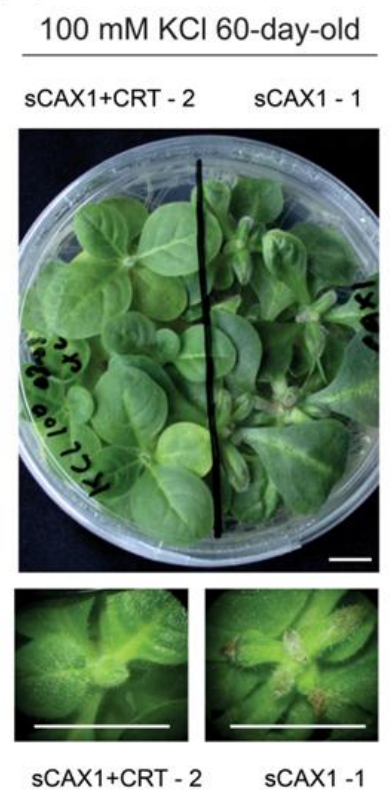

Fig. 5 CRT suppresses $s C A X 1$-induced ion sensitivity in tobacco plants. (a) Tobacco

seedlings grown in medium with low $\mathrm{Ca}^{2+}$ for 30 days. (b) Tobacco seedlings grown in medium with $100 \mathrm{mM} \mathrm{MgCl}_{2}$ for 30 days. (c) Tobacco seedlings grown in medium with $100 \mathrm{mM} \mathrm{KCl}$ for 60 days. Upper panel, overview of the plates; lower panel, close up pictures of $s C A X 1+C R T$ - (lower left) and $s C A X 1$-expressing (lower right) seedlings. Four biological replicates were performed. Scale bar $=1 \mathrm{~cm}$. 